\title{
New Intrathalamic Pathways Allowing Modality-Related and Cross- Modality Switching in the Dorsal Thalamus
}

\author{
John W. Crabtree and John T. R. Isaac \\ Medical Research Council Centre for Synaptic Plasticity, Department of Anatomy, School of Medical Sciences, University \\ of Bristol, Bristol BS8 1TD, United Kingdom
}

\begin{abstract}
Transmission through the dorsal thalamus involves nuclei that convey different aspects of sensory or motor information. Cells in the dorsal thalamus are strongly inhibited by the GABAergic cells of the thalamic reticular nucleus (TRN). Here we show that stimulation of cells in specific dorsal thalamic nuclei evokes robust IPSCs or IPSPs in other specific dorsal thalamic nuclei and vice versa. These IPSCs are $\mathrm{GABA}_{\mathrm{A}}$ receptor-mediated currents and are consistent with the activation of disynaptic intrathalamic pathways mediated by TRN. Thus, cells engaged in sensory analyses in the ventrobasal complex or the medial division of the posterior complex can interact with cells responsive to sensory events in the caudal intralaminar nuclei, whereas cells engaged in motor analyses in the ventrolateral nucleus can interact with cells responsive to motor events in the rostral intralaminar nuclei. Furthermore, sensory eventrelated cells in the caudal intralaminar nuclei can interact with
\end{abstract}

motor event-related cells in the rostral intralaminar nuclei. In addition, single cells in one dorsal thalamic nucleus can receive convergent inhibitory inputs after stimulation of cells in two or more other dorsal thalamic nuclei, and TRN-mediated inhibitory inputs can momentarily switch off tonic firing of action potentials in dorsal thalamic cells. Our findings provide the first direct evidence for a rich network of intrathalamic pathways that allows modality-related and cross-modality inhibitory modulation between dorsal thalamic nuclei. Moreover, TRN-mediated switching between dorsal thalamic nuclei could provide a mechanism for the selection of competing transmissions of sensory and/or motor information through the dorsal thalamus.

Key words: thalamic reticular nucleus; intrathalamic path-

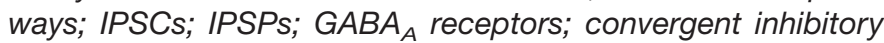
inputs; modality-related and cross-modality modulation; selective attention
The dorsal thalamus is usually thought of as a large collection of nuclei in which each nucleus has its own separate channels through which to transmit sensory or motor information. Such transmission involves first-order nuclei, which receive messages about the sensory or motor periphery through ascending pathways, and higher-order nuclei, which receive messages about cortical processing through descending pathways from cortical layer V (Guillery, 1995; Guillery et al., 1998; Sherman and Guillery, 2001). Both first- and higher-order nuclei project to the cortex, completing corticopetal and corticothalamocortical pathways, respectively. We can tentatively add to this scheme nuclei that contain a mixture of first- and higher-order circuits (Jones, 1985; Macchi and Bentivoglio, 1986; Deschênes et al., 1994; Guillery, 1995; Sherman and Guillery, 2001). These mixed-circuit nuclei are the intralaminar nuclei, which project to both the striatum and cortex (Jones, 1985).

Neurons in the thalamic reticular nucleus (TRN) play a major role in modulating the flow of information through the dorsal thalamus (Sherman and Koch, 1986; Sherman and Guillery, 1996, 2001; Guillery et al., 1998; Crabtree, 1999). These cells are part of the ventral thalamus (Rose, 1942), are GABAergic (Houser et al., 1980), and can exert powerful inhibitory effects on dorsal tha-

\footnotetext{
Received May 16, 2002; revised July 11, 2002; accepted July 15, 2002.

This study was supported by The Wellcome Trust (J.W.C., J.T.R.I.). We thank Andy Griffiths for technical assistance and Bill Anderson for supplying the data acquisition software.

Correspondence should be addressed to John W. Crabtree, Medical Research Council Centre for Synaptic Plasticity, Department of Anatomy, School of Medical Sciences, University of Bristol, Bristol BS8 1TD, UK. E-mail: j.w.crabtree@ bristol.ac.uk.

Copyright (C) 2002 Society for Neuroscience $\quad 0270-6474 / 02 / 228754-08 \$ 15.00 / 0$
}

lamic cells (Salt, 1989; Lee et al., 1994a,b; Warren and Jones, 1994; Cox et al., 1997; Kim and McCormick, 1998). Each dorsal thalamic nucleus is reciprocally connected to TRN (Scheibel and Scheibel, 1966; Jones, 1975, 1985; Guillery et al., 1998; Crabtree, 1999), and these disynaptic pathways form closed- or open-loop circuits (Shosaku, 1986; Lo and Sherman, 1994; Pinault and Deschênes, 1998a; Crabtree, 1999), providing feedback and lateral inhibition, respectively, in a given dorsal thalamic nucleus.

Previously, we showed TRN-mediated pathways between two somatosensory-related dorsal thalamic nuclei, the ventrobasal complex (VB), a first-order nuclear complex, and the medial division of the posterior complex (POm), a higher-order nucleus (Crabtree et al., 1998; Crabtree, 1999). Cells in VB and POm are topographically organized in that rostrally to progressively more caudally located VB and POm cells can interact, reflecting the relatively parallel trajectories of thalamoreticular and reticulothalamic axons that stream within the thalamus and that relate to particular sectors of TRN (Pinault et al., 1995; Deschênes et al., 1996, 1998; Pinault and Deschênes, 1998b) (see Fig. 1). These axonal trajectories suggest that there may be many more TRNmediated pathways in the thalamus. For example, the intrathalamic axons pertaining to the caudal intralaminar nuclei (CIL), a mixed-circuit sensory-related nuclear complex (Albe-Fessard and Besson, 1973; Dong et al., 1978; Peschanski et al., 1981; Grunwerg and Krauthamer, 1992; Berkley et al., 1995; Matsumoto et al., 2001; Minamimoto and Kimura, 2002), overlap such axons pertaining to VB and POm. Similarly, the intrathalamic axons pertaining to the rostral intralaminar nuclei (RIL), a mixed-circuit motor-related nuclear complex (Schlag et al., 1974; Schlag-Rey and Schlag, 1977, 1984; Schlag and Schlag-Rey, 1984), overlap 
such axons pertaining to the ventrolateral nucleus (VL), a firstorder motor nucleus (Jones, 1985; Guillery, 1995; Sherman and Guillery, 2001). Furthermore, TRN cells that are connected to the intralaminar nuclei are intermingled and have a relatively widespread distribution (Jones, 1975; Steriade et al., 1984; Kolmac and Mitrofanis, 1997; Lizier et al., 1997). Therefore, one might expect to find various TRN-mediated pathways that would allow a considerable range of modality-related and cross-modality interactions between populations of dorsal thalamic cells that differ enormously with regard to where their driving afferents originate, their receptive field properties, and where their efferents terminate (Jones, 1985; Macchi and Bentivoglio, 1986; Groenewegen and Berendse, 1994; Guillery, 1995; Sherman and Guillery, 1998, 2001).

Using a thalamic slice preparation, we present evidence for TRN-mediated pathways between cells in the following pairs of dorsal thalamic nuclei: VB and CIL, POm and CIL, VL and RIL, and RIL and CIL. Furthermore, activation of cells in two or more dorsal thalamic nuclei can lead to convergent inputs in cells in another dorsal thalamic nucleus. Finally, tonic firing of action potentials in cells in one dorsal thalamic nucleus can be temporarily switched off by activation of cells in another dorsal thalamic nucleus. Our findings provide direct evidence for a specifically organized network of intrathalamic connections and for a functional role for the interactions within this network.

\section{MATERIALS AND METHODS}

Slice preparation. All experimental procedures were performed in accordance with United Kingdom Home Office regulations (Animals Scientific Procedures Act of 1986). Thirteen- to 20-d-old Wistar rats were deeply anesthetized with sodium pentobarbital (60 mg/kg, i.p.), and their brains were removed and placed in ice-cold extracellular solution. Horizontal thalamic slices (500 $\mu \mathrm{m}$ thick) were cut on a vibratome and were allowed to recover for at least $1 \mathrm{hr}$ at room temperature $\left(23-25^{\circ} \mathrm{C}\right)$. They were then transferred to a recording chamber and submerged beneath continuously superfusing extracellular solution saturated with $95 \% \mathrm{O}_{2}$ and $5 \% \mathrm{CO}_{2}$. The extracellular solution contained the following (in $\mathrm{mM}): 119 \mathrm{NaCl}, 2.5 \mathrm{KCl}, 1.0 \mathrm{NaH}_{2} \mathrm{PO}_{4}, 26.2 \mathrm{NaHCO}_{3}$, and 11.0 glucose, $\mathrm{pH} 7.4$.

Electrophysiology. Whole-cell voltage- and/or current-clamp recordings were made from neurons in VB, POm, VL, CIL, and RIL using 3-5 M 2 glass electrodes. For voltage-clamp recordings, the whole-cell solution contained the following (in $\mathrm{mM}$ ): $135 \mathrm{Cs}$ methane sulfonate, 10.0 HEPES, 0.5 EGTA, 3.0 NaCl, 5.0 QX-314Cl, 4.0 Mg-ATP, 0.3 Na-GTP, and 10.7 biocytin, $\mathrm{pH} 7.2$ with $\mathrm{CsOH}(275 \mathrm{mOsm})$. For current-clamp recordings, the whole-cell solution contained the following (in $\mathrm{mm}$ ): 130 $\mathrm{K}$ methane sulfonate, 5.0 HEPES, 0.2 EGTA, 8.5 NaCl, 4.0 Mg-ATP, 0.5 Na-GTP, and 10.7 biocytin, pH 7.2 with $50 \% \mathrm{KOH}$ (275 mOsm). During recordings, cells were held at $-40 \mathrm{mV}$ (voltage-clamp recordings) or close to $-55 \mathrm{mV}$ (current-clamp recordings). A glass electrode (2.5-3.0 $\mu \mathrm{m}$ tip diameter) was placed in one of the above nuclei and was used to evoke intrathalamic responses in another of the above nuclei. This stimulating electrode was filled with $2 \mathrm{~mm}$ L-glutamate monosodium salt in extracellular solution, $\mathrm{pH} 7.4$, and $5.0 \%$ methylene blue and was connected to a pressure injection unit. Glutamate was ejected by pulses of pressure (5-15 psi; $50 \mathrm{msec}$ duration) at a frequency of $0.05 \mathrm{~Hz}$. When an optimal evoked response was obtained, stimulation was maintained uninterrupted at a constant frequency and intensity for the duration of the experiment.

Recordings were made using an Axopatch-200B amplifier (Axon Instruments, Foster City, CA). Data were filtered at $5 \mathrm{kHz}$, digitalized at 10 $\mathrm{kHz}$, and stored on computer. IPSC amplitudes, input resistance, and series resistance were displayed and analyzed on-line using custom software (Anderson and Collingridge, 2001). IPSC peak amplitudes were measured by averaging across a $25-30 \mathrm{msec}$ window centered on the peak of the response. Data are expressed as percentages of the average baseline amplitude (baseline of 100\%). Pooled data are expressed as means \pm SEM.

Histology and reconstructions. During each recording, the location of

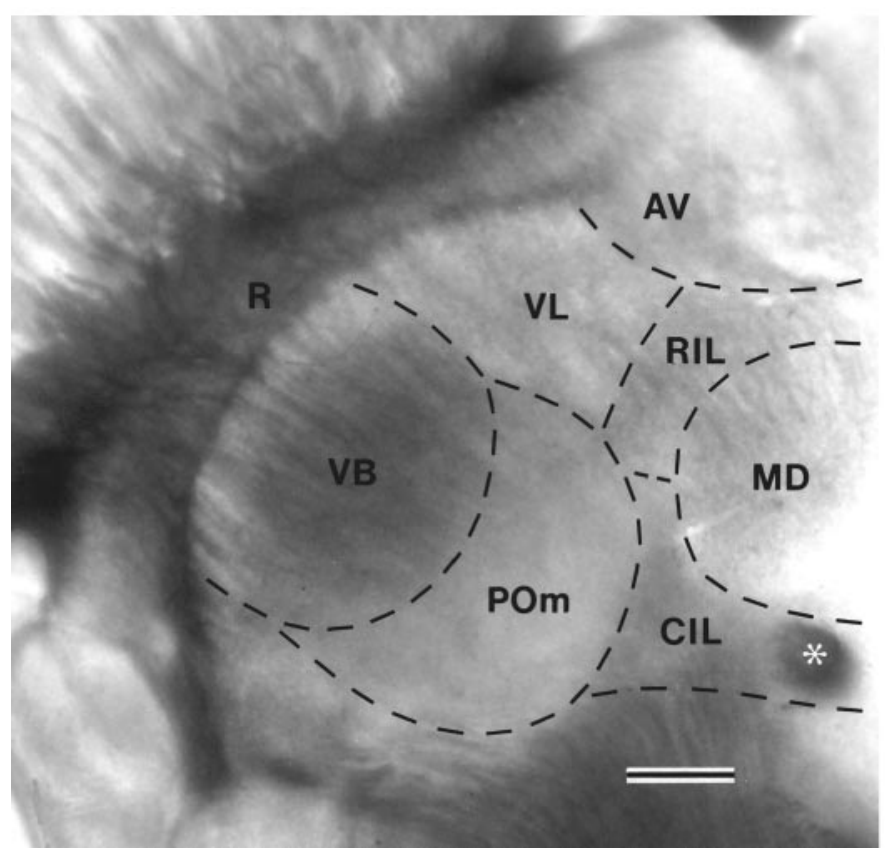

Figure 1. The thalamic slice preparation as it appears in the recording chamber. Transilluminating the slice clearly reveals TRN $(R), \mathrm{VB}, \mathrm{POm}$, VL, RIL, CIL, the anteroventral $(A V)$ and mediodorsal $(M D)$ nuclei, and the retroflex fasciculus (asterisk). The dashed lines indicate the borders of the various nuclei. Rostral is to the top, and medial is to the right. Scale bar, $500 \mu \mathrm{m}$.

the stimulation site, as indicated by the ejected blue dye, and the location of the recording site were drawn on a standardized map of the dorsal thalamus (see Fig. 1). After recordings tracer-filled neurons were processed for biocytin histochemistry using the $\mathrm{ABC}$-diaminobenzidine method (Horikawa and Armstrong, 1988), and the locations of the cells in the dorsal thalamus were confirmed by Nissl counterstaining with cresyl violet.

\section{RESULTS}

\section{Visualization and stimulation of thalamic nuclei}

An in vitro slice preparation (Crabtree et al., 1998) was used to make whole-cell voltage- or current-clamp recordings from neurons in VB, POm, VL, CIL (including the caudal parts of the centrolateral and paracentral nuclei and the parafascicular nucleus), and RIL (including the rostral parts of the centrolateral and paracentral nuclei), and the responses of these cells to stimulation of the dorsal thalamus were monitored. By cutting slices in the horizontal plane, intrathalamic connections linking TRN to VB, POm, VL, CIL, and RIL were preserved, whereas connections between the thalamus and the cortex were severed. The slices were transilluminated from below using two orthogonal reflective surfaces, which resulted in contrast interference patterns that clearly revealed the nuclei of the thalamus (Fig. 1) and which enabled the appropriate positioning of the recording and stimulating electrodes. Dorsal thalamic neurons were stimulated using local application of glutamate, which activated cell bodies but not axons of passage (Crabtree et al., 1998). During an experiment, the inclusion of a blue dye in the stimulating solution allowed the location of the stimulation site and the spread of the stimulating solution to be visualized.

\section{Response of sensory-related dorsal thalamic cells to dorsal thalamic stimulation}

Initially, we examined the possibility that intrathalamic pathways exist between sensory-related dorsal thalamic nuclei besides the 
Figure 2. Glutamate stimulation in a sensory or motor dorsal thalamic nucleus evokes IPSCs in cells in another sensory or motor dorsal thalamic nucleus. $A$, Example of an IPSC recorded from a VB cell in response to glutamate stimulation in CIL ( $\mathrm{CIL} \rightarrow \mathrm{VB}) . B, \mathrm{Ex}-$ ample of an IPSC recorded from a VL cell in response to glutamate stimulation in RIL (RIL $\rightarrow$ VL). Calibration also applies to $A$. $C$, Example of an IPSC recorded from an RIL cell in response to glutamate stimulation in CIL ( $\mathrm{CIL} \rightarrow$ RIL). Glutamate stimulation is indicated by the black bars in $A-C$. D, The biocytin-filled VB cell from which the recording in $A$ was obtained. $E$, The biocytin-filled VL cell from which the recording in $B$ was obtained. $F$, The biocytin-filled RIL cell from which the recording in $C$ was obtained. $G$, Horizontal section through the thalamus showing the locations of the recorded cell in VB (black dot) shown in $D$ and the stimulation site in CIL (open circle). $H$, Horizontal section through the thalamus showing the locations of the recorded cell in VL (black dot) shown in $E$ and the stimulation site in RIL (open circle). I, Horizontal section through the thalamus showing the locations of the recorded cell in RIL (black dot) shown in $F$ and the stimulation site in CIL (open circle). Rostral is to the top, and medial is to the right $(G-I)$. Scale bars: $G-I, 500 \mu \mathrm{m}$.

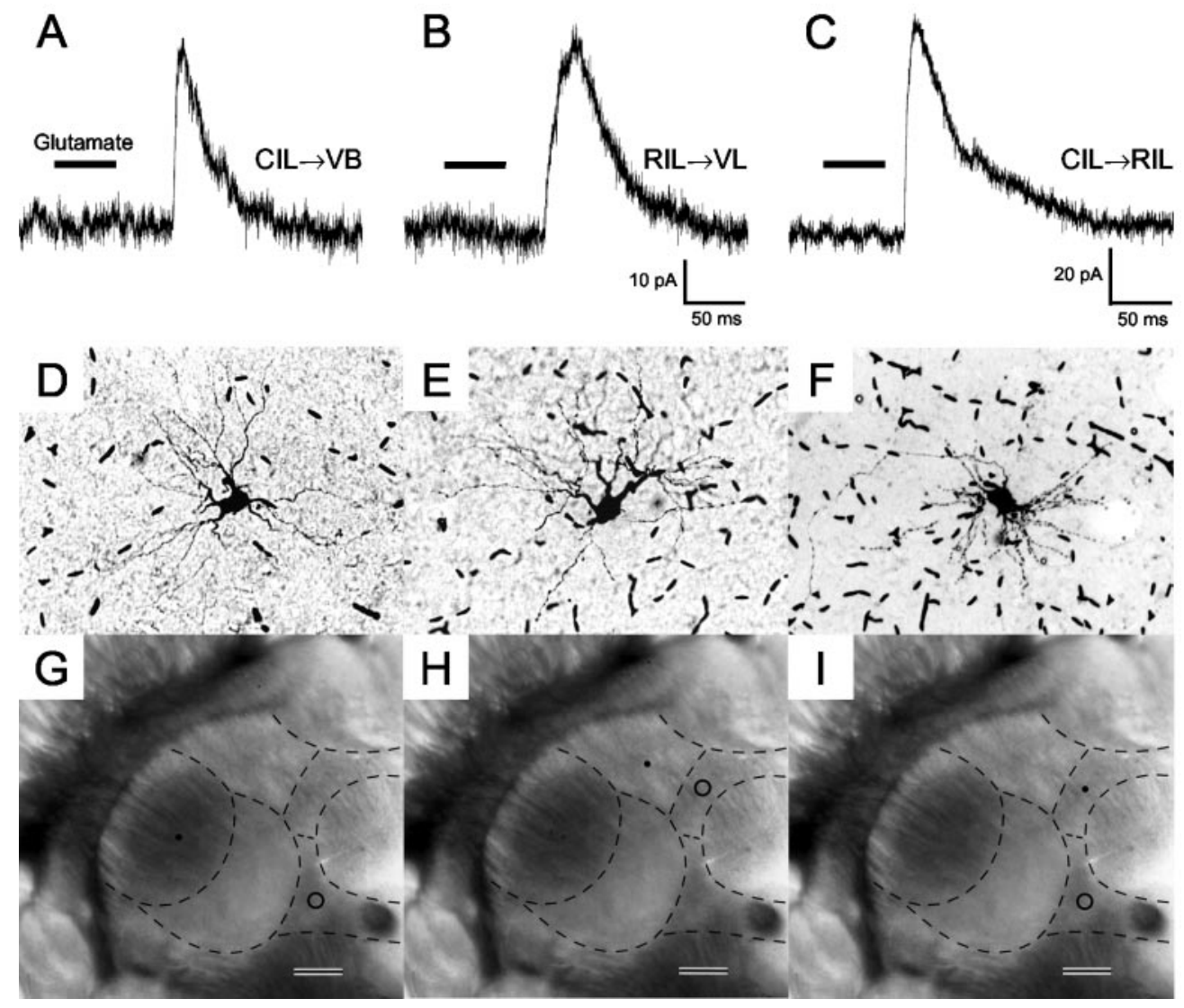

pathways between VB and POm (Crabtree et al., 1998; Crabtree, 1999). Robust IPSCs (Fig. $2 A$ ) were recorded in seven VB cells (Fig. $2 D, G$ ) and seven POm cells in response to glutamate stimulation in CIL (Fig. 2G) and in 14 CIL cells in response to glutamate stimulation in VB or POm. Here and elsewhere, these IPSCs had an amplitude that varied between 20 and 120 pA and rose rapidly. The IPSCs were always substantially larger than spontaneous IPSCs, if present, and were evoked with a constant latency typically between 50 and $100 \mathrm{msec}$ relative to the beginning of the glutamate pulse. A proportion of this latency presumably included the time required for the glutamate to reach and activate the appropriately connected dorsal thalamic cells. The presence of these pathways suggests that there can be reciprocal modulation of transmission between sensory-related VB or POm and CIL in addition to the possibility of such modulation between $\mathrm{VB}$ and POm.

\section{Response of motor-related dorsal thalamic cells to dorsal thalamic stimulation}

We next explored the possibility that intrathalamic pathways exist between motor-related dorsal thalamic nuclei. Robust IPSCs (Fig. 2B) were recorded in eight VL cells (Fig. 2E,H) in response to glutamate stimulation in RIL (Fig. $2 H$ ) and in eight RIL cells in response to glutamate stimulation in VL. The existence of these pathways suggests that, in addition to modulation between sensory-related nuclei, there can be reciprocal modulation of transmission between motor-related VL and RIL.

\section{Response of sensory- or motor-related dorsal thalamic cells to dorsal thalamic stimulation}

We then examined the possibility that intrathalamic pathways exist between sensory- and motor-related dorsal thalamic nuclei.
Robust IPSCs (Fig. 2C) were recorded in eight RIL cells (Fig. $2 F, I$ ) in response to glutamate stimulation in CIL (Fig. $2 I$ ) and in eight CIL cells in response to glutamate stimulation in RIL. The presence of these pathways suggests that, in addition to modulation between sensory-related nuclei and between motor-related nuclei, there can be reciprocal modulation of transmission between sensory-related CIL and motor-related RIL.

After an experiment, recovery of biocytin-filled cells (Figs. $2 D-F$ ) (see also Fig. $5 B, D, H$ ) and Nissl counterstaining (Fig. $3 A-C$ ) confirmed the locations of recorded cells in $\mathrm{VB}, \mathrm{POm}, \mathrm{VL}$, CIL, or RIL. For each of the above sensory-, motor-, and sensoryand motor-related pathways, there was a topographic relationship between the location of a responsive cell and the location of the stimulating electrode that evoked the response. That is, stimulating in rostrally to progressively more caudally located sites evoked IPSCs in rostrally to progressively more caudally located cells (Fig. 3D). The division of the intralaminar nuclei into two regions (Fig. 1, dashed line) was purely functional in that only cells lying in the region designated CIL interacted with VB or POm cells and only cells lying in the region designated RIL interacted with VL cells. Furthermore, glutamate stimulation never evoked EPSCs in a recorded cell, indicating that there are no direct connections between the nuclei we examined.

It is important to note here that, although we routinely attempted to activate them, IPSCs could not be evoked between cells in the following pairs of nuclei: VB and VL, VB and RIL, POm and VL, POm and RIL, and VL and CIL (see Fig. 7). Therefore, cells in these nuclear pairs would not be expected to modulate the transmission of each other. The absence of intrathalamic connections between specific pairs of dorsal thalamic nuclei 


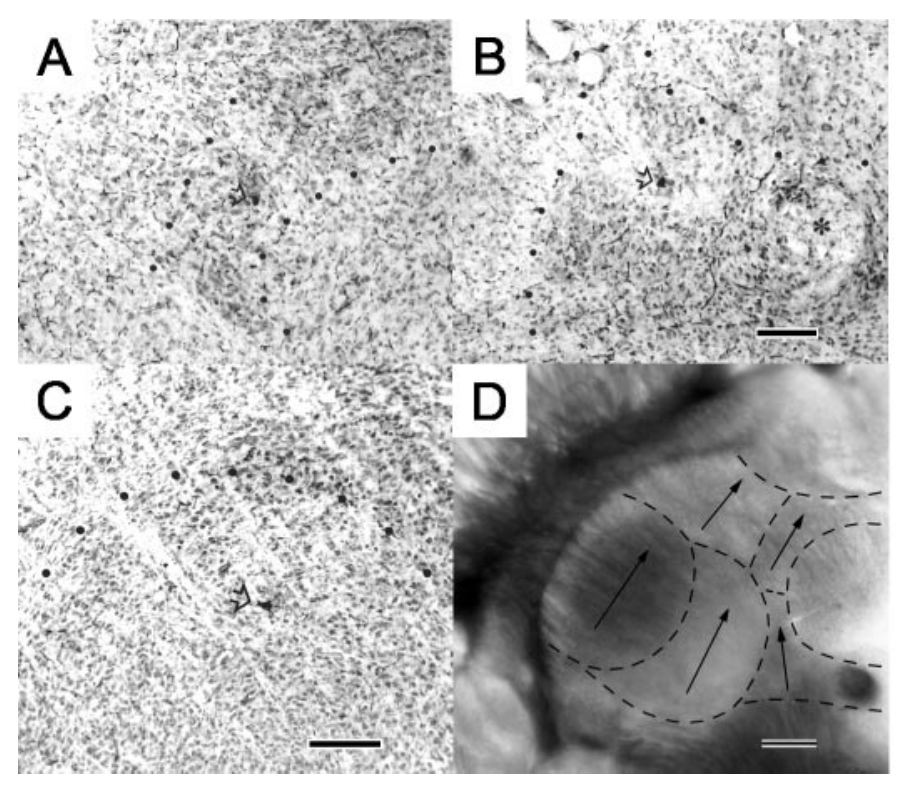

Figure 3. Stimulation and recording sites are topographically organized between dorsal thalamic nuclei. $A$, Horizontal section through the thalamus showing Nissl staining. The arrow points to the biocytin-filled RIL cell shown in Figure 5D. The black dots indicate the borders between RIL and VL (left) and RIL and the mediodorsal nuclei (bottom right). B, Horizontal section through the thalamus showing Nissl staining. The arrow points to the biocytin-filled CIL cell shown in Figure $5 \mathrm{H}$. The black dots indicate the borders between CIL and POm (left) and CIL and the mediodorsal nuclei (top right). The asterisk indicates the retroflex fasciculus. $C$, Horizontal section through the thalamus showing Nissl staining. The arrow points to a biocytin-filled VB cell. The black dots indicate the borders between VB and TRN (top left) and VB and VL (top right). D, Horizontal section through the thalamus showing a summary of the topographic relationship between stimulation sites (arrows) and recording sites (arrows) in various dorsal thalamic nuclei. The corresponding directions of the arrows indicate the locations of the stimulating electrode in one dorsal thalamic nucleus and of cells in another dorsal thalamic nucleus in which a response was evoked. Rostral is to the top, and medial is to the right $(A-D)$. Scale bars: (in $B) A, B, 200 \mu \mathrm{m} ; C, 200 \mu \mathrm{m} ; D$, $500 \mu \mathrm{m}$.

may provide an important clue as to the function of such connections between other specific pairs of dorsal thalamic nuclei.

\section{Characterization of the response evoked in dorsal thalamic cells}

The IPSCs were reversibly antagonized by the competitive $\mathrm{GABA}_{\mathrm{A}}$ antagonist bicuculline $(10 \mu \mathrm{M})$. After the collection of a stable baseline of IPSCs, bicuculline was bath applied for $10 \mathrm{~min}$, which blocked the response, and, on washout, the IPSCs returned (Fig. 4A). Summary data for 10 cells (Fig. 4B) show that bicuculline caused a reduction in IPSC amplitude to $4 \pm 1 \%$ of baseline and, on washout, the amplitude recovered to $81 \pm 14 \%$.

\section{Convergence of inhibitory inputs onto dorsal thalamic cells}

The above results together with those from our previous study (Crabtree et al., 1998) suggest that activation of cells in two or more dorsal thalamic nuclei could result in convergent inhibitory inputs onto single cells in another dorsal thalamic nucleus (see Fig. 7). This possibility was examined in eight additional dorsal thalamic cells. IPSCs were initially recorded in a cell in one dorsal thalamic nucleus in response to glutamate stimulation in another dorsal thalamic nucleus. Then the stimulating electrode was repositioned and IPSCs were recorded in the same cell to
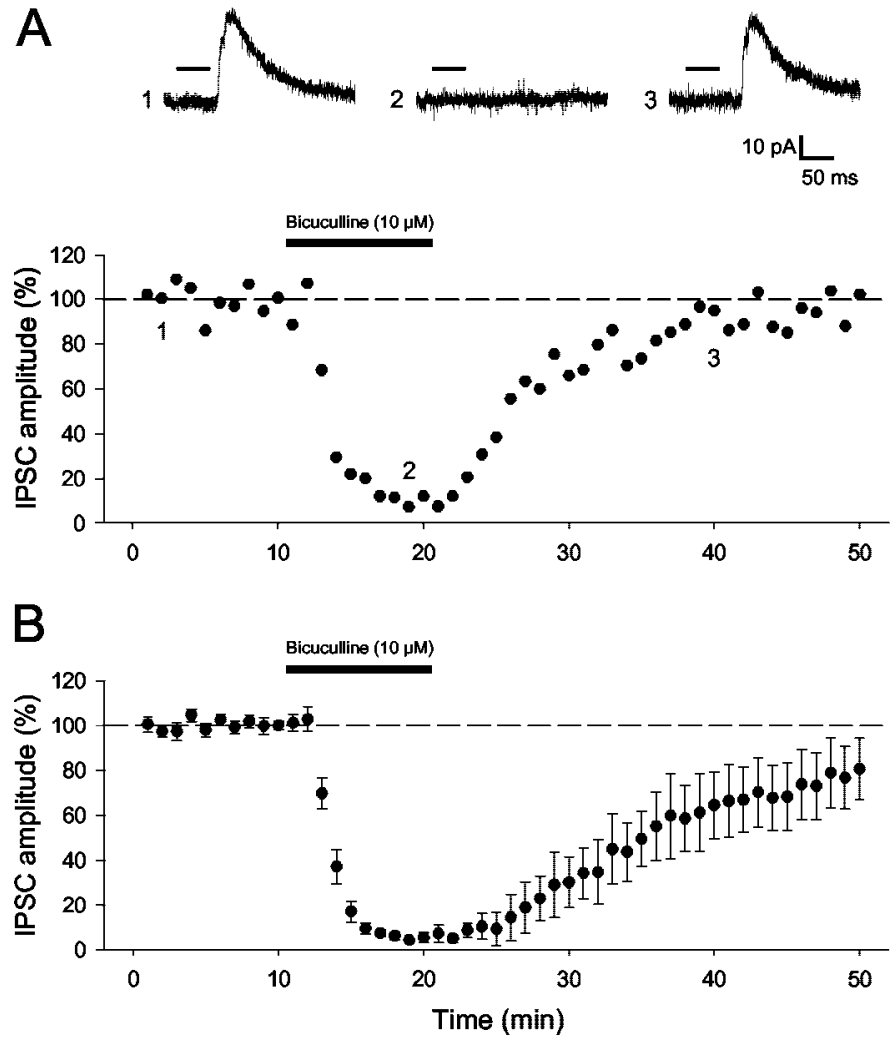

Figure 4. Bicuculline blocks the IPSCs evoked in cells in one dorsal thalamic nucleus by glutamate stimulation in another dorsal thalamic nucleus. A, Amplitude of IPSCs, evoked in a CIL cell by glutamate stimulation in $\mathrm{VB}$, versus time from an example experiment in which bicuculline was bath applied (black bar). Top. Individual traces taken at the times indicated $(1,2,3)$ during the experiment; glutamate stimulation is indicated by the black bars. $B$, Summary graph of the effect of bicuculline (black bar) on the evoked IPSCs from 10 experiments in which each pair of interacting dorsal thalamic nuclei is represented at least once. Dashed line indicates the baseline response level (100\%) in $A$ and $B$.

glutamate stimulation in yet another dorsal thalamic nucleus and so forth. In this manner, IPSCs were recorded in single VB cells in response to sequential glutamate stimulation in POm and CIL, and IPSCs (Fig. $5 A$ ) were recorded in single POm cells (Fig. $5 B, E)$ in response to sequential glutamate stimulation in $\mathrm{VB}$ and CIL (Fig. 5E). Furthermore, IPSCs (Fig. 5C) were recorded in single RIL cells (Fig. $5 D, F$ ) in response to sequential glutamate stimulation in VL and CIL (Fig. $5 F$ ). And finally, IPSCs (Fig. $5 G$ ) were recorded in single CIL cells (Fig. $5 H, I$ ) in response to sequential glutamate stimulation in VB, POm, and RIL (Fig. 5I). Such convergence of inhibitory inputs suggests that transmission through single cells in one dorsal thalamic nucleus can be modulated by cells in two or more other dorsal thalamic nuclei.

\section{Interruption of tonic firing in dorsal thalamic cells}

To examine a possible functional role for the intrathalamic pathways, whole-cell recordings were made from 16 additional dorsal thalamic cells and their properties were investigated in both voltage- and current-clamp modes. Each pair of interacting dorsal thalamic nuclei was examined at least once. In a typical experiment, IPSCs (Fig. 6A) were initially recorded in voltage-clamp mode in a cell in one dorsal thalamic nucleus (Fig. 6B) in response to glutamate stimulation in another dorsal thalamic nucleus (Fig. 6B). Then, in current-clamp mode, a train of action 

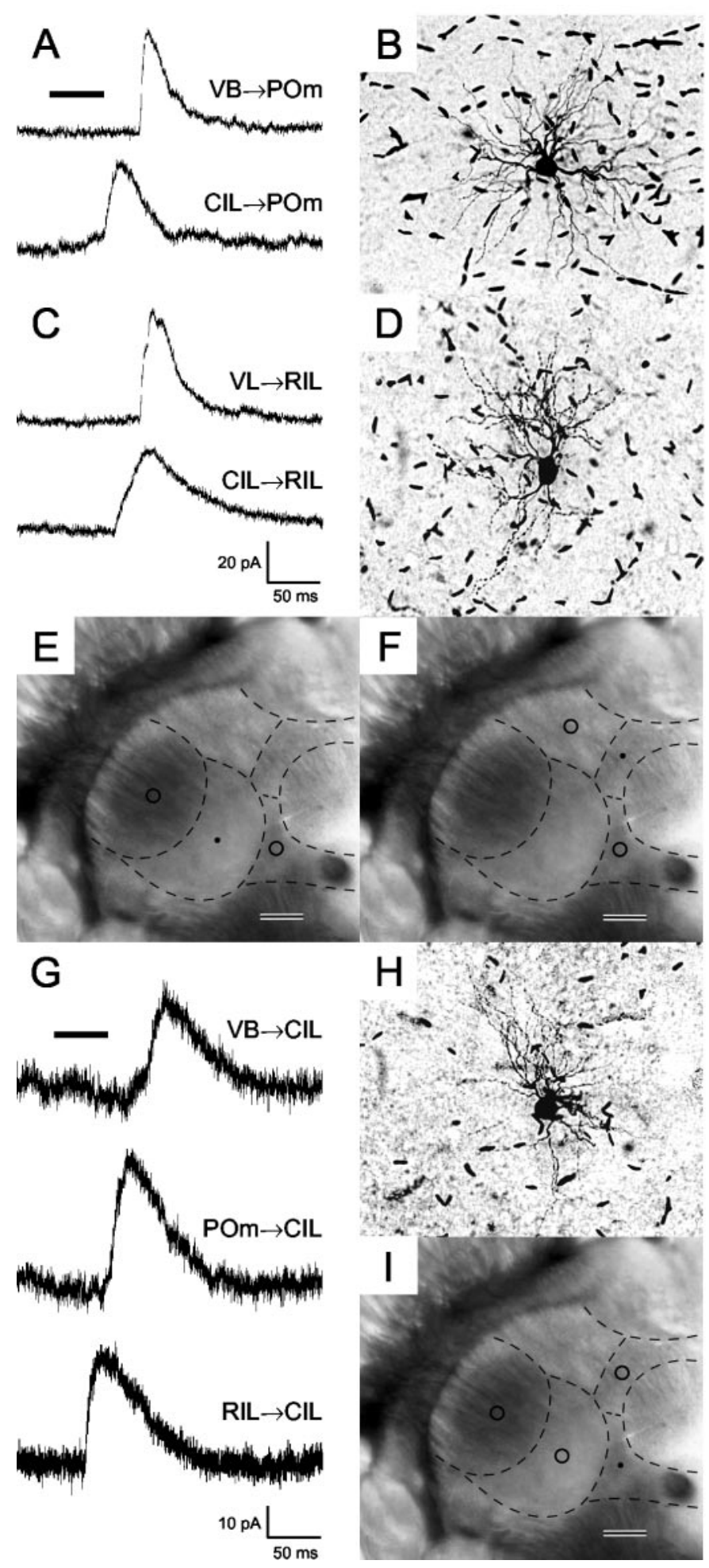

Figure 5. Glutamate stimulation in two or more dorsal thalamic nuclei evokes IPSCs in single cells in another dorsal thalamic nucleus. $A$, Examples of IPSCs recorded from a POm cell in response to glutamate stimulation in $\mathrm{VB}(\mathrm{VB} \rightarrow \mathrm{POm}$, top trace) and in $\mathrm{CIL}(\mathrm{CIL} \rightarrow \mathrm{POm}$, bottom trace). $B$, The biocytin-filled POm cell from which the recordings in $A$ were obtained. $C$, Examples of IPSCs recorded from an RIL cell in response to glutamate stimulation in $\mathrm{VL}(\mathrm{VL} \rightarrow \mathrm{RIL}$, top trace) and in $\mathrm{CIL}$ $(\mathrm{CIL} \rightarrow \mathrm{RIL}$, bottom trace $)$. Glutamate stimulation is indicated by the black bar (top and bottom traces: $A, C$ ). Calibration also applies to $A$. $D$, The biocytin-filled RIL cell (see Fig. $3 A$ ) from which the recordings in $C$ were obtained. $E$, Horizontal section through the thalamus showing the locations of the recorded cell in POm (black dot) shown in $B$ and the

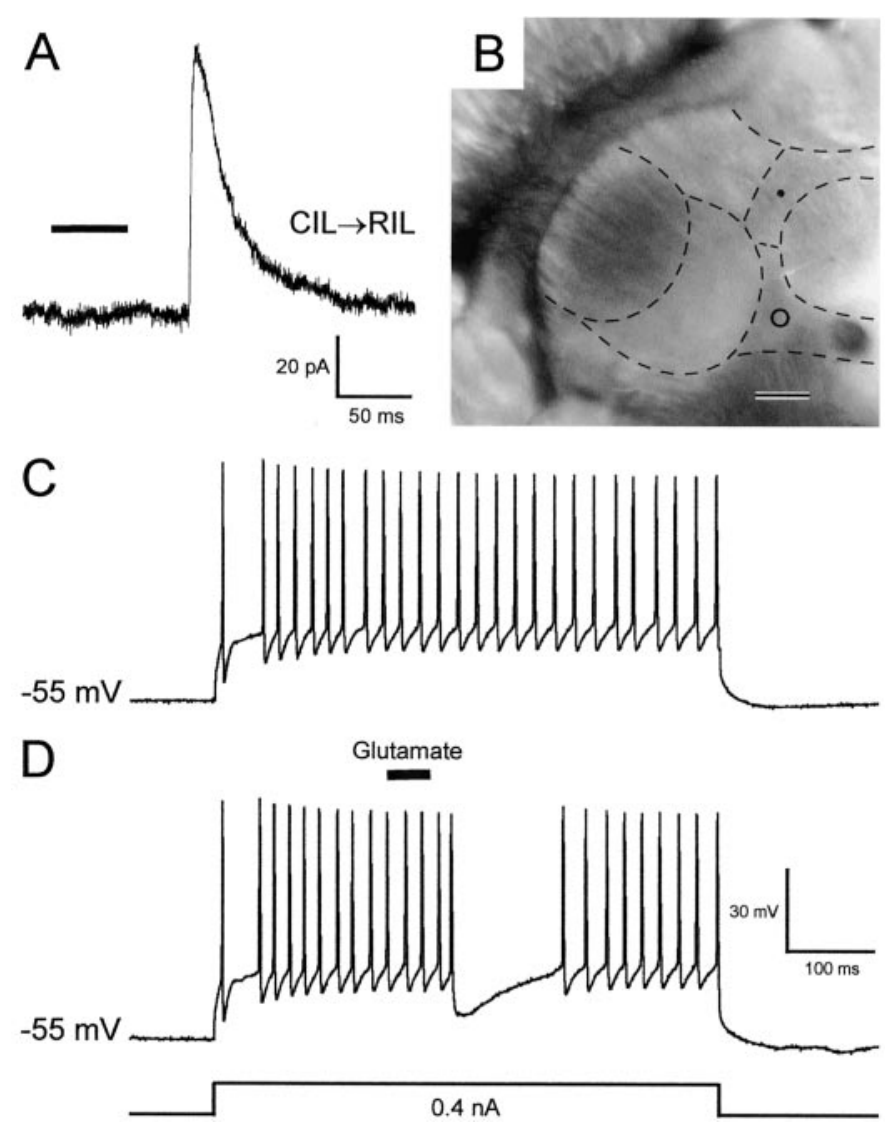

Figure 6. Glutamate stimulation in one dorsal thalamic nucleus interrupts trains of action potentials in cells in another dorsal thalamic nucleus. $A$, An example of an IPSC recorded from an RIL cell in response to glutamate stimulation (black bar) in CIL (CIL $\rightarrow$ RIL). B, Horizontal section through the thalamus showing the locations of the recorded cell in RIL (black dot) and the stimulation site in CIL (open circle). Rostral is to the top, and medial is to the right. Scale bar, $500 \mu \mathrm{m}$. $C$, When held close to $-55 \mathrm{mV}$, the RIL cell responded with a train of action potentials to a depolarizing $0.4 \mathrm{nA}$ current pulse (bottom) injected into the cell. $D, \mathrm{~A}$ train of action potentials in the RIL cell to the depolarizing current pulse was interrupted by glutamate stimulation (black bar) in CIL.

potentials was evoked in the cell using a depolarizing current pulse (Fig. 6C). When combining the stimulation with the depolarizing current pulse, the glutamate stimulation interrupted the action potentials for $\sim 100 \mathrm{msec}$ (Fig. $6 D$ ). The functional implication of this interruption of action potentials is that cells in interacting pairs of dorsal thalamic nuclei can temporarily switch off the activity of each other.

stimulation sites in VB (left open circle) and CIL (right open circle). F, Horizontal section through the thalamus showing the locations of the recorded cell in RIL (black dot) shown in $D$ and the stimulation sites in VL (top open circle) and CIL (bottom open circle). G, Examples of IPSCs recorded from a CIL cell in response to glutamate stimulation in VB ( $\mathrm{VB} \rightarrow \mathrm{CIL}$, top trace), in $\mathrm{POm}(\mathrm{POm} \rightarrow \mathrm{CIL}$, middle trace), and in $\mathrm{RIL}$ $(\mathrm{RIL} \rightarrow \mathrm{CIL}$, bottom trace). Glutamate stimulation is indicated by the black bar (top, middle, and bottom traces). H, The biocytin-filled CIL cell (see Fig. $3 B$ ) from which the recordings in $G$ were obtained. $I$, Horizontal section through the thalamus showing the locations of the recorded cell in CIL (black dot) shown in $H$ and the stimulation sites in VB (left open circle), POm (bottom middle open circle), and RIL (top right open circle). Rostral is to the top, and medial is to the right $(E, F, I)$. Scale bars: $E, F$, $I, 500 \mu \mathrm{m}$. 


\section{DISCUSSION}

\section{A network of intrathalamic pathways}

Using electrophysiological recordings in a thalamic slice preparation, we show that glutamate stimulation of sensory-related cells in VB or POm evokes IPSCs in sensory-related cells in CIL and vice versa. Next we show that glutamate stimulation of motorrelated cells in VL (or RIL) evokes IPSCs in motor-related cells in RIL (or VL). We then go on to show that glutamate stimulation of sensory-related cells in CIL evokes IPSCs in motorrelated cells in RIL and vice versa. These IPSCs are GABA receptor-mediated currents, and single cells in one dorsal thalamic nucleus can receive convergent inhibitory inputs after activation of cells in two or more other dorsal thalamic nuclei. Furthermore, the inhibitory inputs can interrupt, or momentarily switch off, tonic firing of action potentials in dorsal thalamic cells. Our data provide strong evidence for a rich network of intrathalamic pathways that allow modality-related and cross-modality modulation of the flow of information through various first-order, higher-order, and mixed-circuit nuclei in the dorsal thalamus.

\section{The thalamic reticular nucleus mediates the intrathalamic pathways}

The IPSCs evoked in dorsal thalamic cells can be entirely accounted for by the activation of disynaptic pathways mediated by the GABAergic cells of TRN. The IPSCs cannot be explained by the activation of polysynaptic pathways involving the cerebral cortex or the GABAergic cells of the zona incerta (Oertel et al., 1982; Power et al., 1999) or substantia nigra (MacLeod et al., 1980; Oertel et al., 1982; Kha et al., 2001), because the thalamic slices were cut in a plane that would sever such connections, nor can the activation of disynaptic circuits between a single dorsal thalamic nucleus and TRN (e.g., RIL to TRN to RIL) account for the IPSCs, because the glutamate stimulation sites were always restricted to a dorsal thalamic nucleus other than the one containing the recorded cell. The IPSCs also cannot be explained by the activation of a monosynaptic pathway from TRN to a given dorsal thalamic nucleus, because glutamate stimulation selectively activated cell bodies but not reticulothalamic axons of passage. Furthermore, in those experiments in which the stimulating electrode was placed in VB or VL adjacent to TRN, the stimulation site was always at least $300 \mu \mathrm{m}$ away from the inner border of TRN but the stimulating solution containing the blue dye never spread $>100 \mu \mathrm{m}$ within the thalamus. Finally, because all of the dorsal thalamic nuclei we studied lack GABAergic interneurons (Houser et al., 1980; Barbaresi et al., 1986; Bentivoglio et al., 1991; Arcelli et al., 1997), cells in TRN are the only intrathalamic source of GABAergic afferents in our slice preparation. The above considerations strongly indicate that the IPSCs recorded in this study resulted from the activation of various TRN-mediated pathways connecting one dorsal thalamic nucleus to another. We saw no evidence for direct glutamatergic pathways between any of the dorsal thalamic nuclei studied here.

\section{The thalamic reticular nucleus allows modality-related and cross-modality modulation}

The TRN-mediated pathways shown here and previously (Crabtree et al., 1998; Crabtree, 1999) link together five pairs of dorsal thalamic nuclei (Fig. 7) that are engaged in the transmission of different aspects of sensory or motor information. VB cells have relatively small receptive fields and convey information about mechanical stimulation of the contralateral skin or deep tissues (Jones, 1985). POm cells have larger receptive fields than

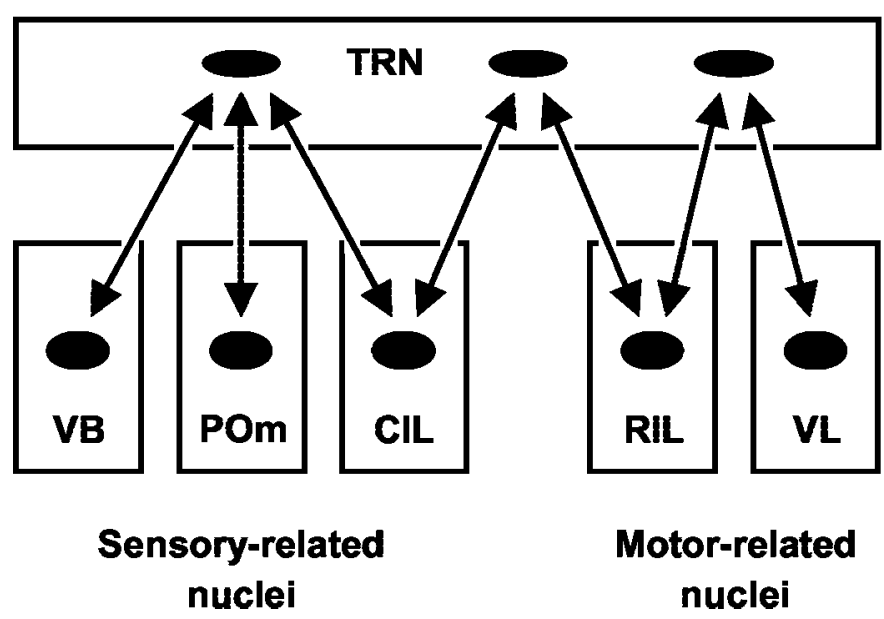

Figure 7. Schematic drawing showing the intrathalamic pathways described here and previously (Crabtree et al., 1998; Crabtree, 1999). These pathways link together cells (black ovals) in VB and POm, VB and CIL, POm and CIL, CIL and RIL, and RIL and VL through cells (black ovals) in TRN.

VB cells and convey information about cortical processing in the ipsilateral somatosensory cortical area 1 (Diamond et al., 1992a,b). Such processing includes inputs from motor cortical area 1 (Porter and White, 1983; Miyashita et al., 1994). CIL cells have extremely large bilateral receptive fields and convey information about sensory events (Albe-Fessard and Besson, 1973; Dong et al., 1978; Peschanski et al., 1981; Grunwerg and Krauthamer, 1992; Berkley et al., 1995; Matsumoto et al., 2001; Minamimoto and Kimura, 2002). These cells can have multimodal receptive fields (somatosensory, auditory, and visual), suitable for transmitting the occurrence of new and potentially interesting sensory events, or can respond to cutaneous or deep noxious stimuli, suitable for transmitting the occurrence of potentially harmful events. VL cells have relatively small motor fields and convey information about proprioceptive stimulation of contralateral deep tissues related to movement around a single joint and often of a single muscle (Strick, 1976; Vitek et al., 1994, 1996). RIL cells have bilateral oculomotor fields or extremely large unilateral receptive fields and convey information about motor events (Schlag et al., 1974; Schlag-Rey and Schlag, 1977, 1984; Schlag and Schlag-Rey, 1984). These cells can respond to anticipated or actual eye movements or can respond to changes in or the sudden appearance of a visual target that elicits eye movements to or fixation of the eyes on the target. Thus, this linkage between the five pairs of nuclei makes ample allowance for a broad range of modality-related and cross-modality modulation of transmission through the dorsal thalamus.

\section{Specificity of thalamic reticular-mediated connectivity}

The TRN-mediated linkage of five pairs of dorsal thalamic nuclei could be construed as an example of intrathalamic connectivity underlying widespread interactions among cells in the dorsal thalamus. On the contrary, in this same group of dorsal thalamic nuclei, we found no evidence for interactions between cells in five other nuclear pairs (e.g., between VB and VL). Furthermore, for any given pair of interacting nuclei, there is a strict topographic relationship between the locations of stimulation sites and responsive cells (Fig. 3D). Such topography suggests that internuclear modulation of transmission could occur simultaneously in multiple homologous regions in pairs of interacting nuclei. 


\section{Thalamic reticular-mediated connectivity: closed- or open-loop circuits?}

Cells in each pair or trio of interacting dorsal thalamic nuclei could access a single population of TRN cells (Fig. 7). However, more complex patterns of connectivity are possible. For example, cells in each dorsal thalamic nucleus in an interaction could engage a separate population of TRN cells or could engage a population of TRN cells that is partially shared by cells in one or more other dorsal thalamic nuclei. The actual patterns of connectivity of these intrathalamic pathways will determine whether they form internuclear closed-loop circuits, in which a cell in one dorsal thalamic nucleus inhibits and is inhibited by the same cell in another dorsal thalamic nucleus, or internuclear open-loop circuits, in which a cell in one dorsal thalamic nucleus inhibits and is inhibited by different cells in another dorsal thalamic nucleus.

\section{Convergence of thalamic reticular-mediated inputs}

After activation of cells in two or more dorsal thalamic nuclei, inhibitory inputs could converge onto separate populations of cells in another dorsal thalamic nucleus. Thus, one nucleus could engage in simultaneous reciprocal modulation with two or more other nuclei. Alternatively, activation of cells in two or more dorsal thalamic nuclei can lead to convergence of inhibitory inputs onto single cells in another dorsal thalamic nucleus (Fig. $5 A, C, G)$. The temporal pattern of the activation of these inputs could determine the response mode of the cell (Deschênes et al., 1984; Jahnsen and Llinás, 1984; Sherman, 2001; Sherman and Guillery, 2001). When the cell is at rest, near simultaneous activation of the inputs could generate large and long-lasting IPSPs that would result from $\mathrm{GABA}_{\mathrm{A}}$ and potentially $\mathrm{GABA}_{\mathrm{B}}$ (Crunelli and Leresche, 1991; Sanchez-Vives and McCormick, 1997) receptor activation. The resulting prolonged hyperpolarization could be sufficient to de-inactivate the low-threshold T-type $\mathrm{Ca}^{2+}$ channels, thus priming the cell to fire in burst mode to a depolarizing EPSP.

\section{Thalamic reticular-mediated switching: a mechanism for selective attention?}

There has been much speculation about a role for TRN in selective attention (Skinner and Yingling, 1977; Scheibel, 1981; Crick, 1984; LaBerge et al., 1992; Guillery et al., 1998). Here we show that activation of cells in one dorsal thalamic nucleus can lead to IPSPs that temporarily switch off tonic firing of action potentials in cells in another dorsal thalamic nucleus (Fig. 6D). This TRN-mediated switching between cells in two dorsal thalamic nuclei could provide a mechanism for selection between competing processes for limited attentional resources (Desimone and Duncan, 1995). That is, depending on the relative salience of messages reaching the dorsal thalamus at any given moment, transmission would be selected through cells in only one of two given homologous regions in a pair of interacting nuclei. This selectivity of transmission could partition transfer of information through different dorsal thalamic nuclei into discrete temporal components, reflecting the ever-changing attentional demands of the external and internal sensory and motor environment. Furthermore, this selection could prevent simultaneous transmission of attentionally incompatible combinations of messages through the dorsal thalamus. Accordingly, our findings predict that (1) nuclei conveying messages about peripheral sensory analyses (e.g., VB) (Jones, 1985) would compete with nuclei conveying messages about cortical sensory analyses (e.g., POm) (Diamond et al., 1992a,b), (2) nuclei conveying messages about sensory (e.g.,
VB or POm) or motor (e.g., VL) (Strick, 1976; Vitek et al., 1994, 1996) analyses would compete, respectively, with nuclei conveying messages about the occurrence of new sensory (CIL) (AlbeFessard and Besson, 1973; Dong et al., 1978; Peschanski et al., 1981; Grunwerg and Krauthamer, 1992; Berkley et al., 1995; Matsumoto et al., 2001; Minamimoto and Kimura, 2002) or motor (RIL) (Schlag et al., 1974; Schlag-Rey and Schlag, 1977, 1984; Schlag and Schlag-Rey, 1984) events, and (3) CIL and RIL would compete with each other for the conveyance of messages about new sensory or motor events. Thus, the dorsal thalamus can no longer be thought of as containing nuclei with their own independent channels of communication. Instead, dorsal thalamic nuclei in each of several specific pairs can interact through TRN, temporarily and competitively switching off the transmission of information of each other.

\section{REFERENCES}

Albe-Fessard D, Besson JM (1973) Convergent thalamic and cortical projections-the non-specific system. In: Handbook of sensory physiology, Vol II, Somatosensory system (Iggo A, ed), pp 489-560. New York: Springer.

Anderson WW, Collingridge GL (2001) The LTP program: a data acquisition program for on-line analysis of long-term potentiation and other synaptic events. J Neurosci Methods 108:71-83.

Arcelli P, Frassoni C, Regondi MC, De Biasi S, Spreafico R (1997) GABAergic neurons in mammalian thalamus: a marker of thalamic complexity? Brain Res Bull 42:27-37.

Barbaresi P, Spreafico R, Frassoni C, Rustioni A (1986) GABAergic neurons are present in the dorsal column nuclei but not in the ventroposterior complex of rats. Brain Res 382:305-326.

Bentivoglio M, Spreafico R, Minciacchi D, Macchi G (1991) GABAergic interneurons and neuropil of the intralaminar thalamus: an immunohistochemical study in the rat and the cat, with notes in the monkey. Exp Brain Res 87:85-95.

Berkley KJ, Benoist J-M, Gautron M, Guilbaud G (1995) Responses of neurons in the caudal intralaminar thalamic complex of the rat to stimulation of the uterus, vagina, cervix, colon, and skin. Brain Res 695:92-95.

Cox CL, Huguenard JR, Prince DA (1997) Nucleus reticularis neurons mediate diverse inhibitory effects in thalamus. Proc Natl Acad Sci USA 94:8854-8859.

Crabtree JW (1999) Intrathalamic sensory connections mediated by the thalamic reticular nucleus. Cell Mol Life Sci 56:683-700.

Crabtree JW, Collingridge GL, Isaac JTR (1998) A new intrathalamic pathway linking modality-related nuclei in the dorsal thalamus. Nat Neurosci 1:389-394.

Crick F (1984) Function of the thalamic reticular complex: the searchlight hypothesis. Proc Natl Acad Sci USA 81:4586-4590.

Crunelli V, Leresche N (1991) A role for $\mathrm{GABA}_{\mathrm{B}}$ receptors in excitation and inhibition of thalamocortical cells. Trends Neurosci 14:16-21.

Deschênes M, Paradis M, Roy JP, Steriade M (1984) Electrophysiology of neurons of lateral thalamic nuclei in cat: resting properties and burst discharges. J Neurophysiol 51:1196-1219.

Deschênes M, Bourassa J, Pinault D (1994) Corticothalamic projections from layer $\mathrm{V}$ cells in rat are collaterals of long-range corticof ugal axons. Brain Res 664:215-219.

Deschênes M, Bourassa J, Doan VD, Parent A (1996) A single-cell study of the axonal projections arising from the posterior intralaminar thalamic nuclei in the rat. Eur J Neurosci 8:329-343.

Deschênes M, Veinante P, Zhang Z-W (1998) The organization of corticothalamic projections: reciprocity versus parity. Brain Res Rev 28:286-308.

Desimone R, Duncan J (1995) Neural mechanisms of selective visual attention. Annu Rev Neurosci 18:193-222.

Diamond ME, Armstrong-James M, Ebner FF (1992a) Somatic sensory responses in the rostral sector of the posterior group (POm) and the ventral posterior medial nucleus (VPM) of the rat thalamus. J Comp Neurol 318:462-476.

Diamond ME, Armstrong-James M, Budway MJ, Ebner FF (1992b) Somatic sensory responses in the rostral sector of the posterior group (POm) and in the ventral posterior medial nucleus (VPM) of the rat thalamus: dependence on the barrel field cortex. J Comp Neurol 319:66-84.

Dong WK, Ryu H, Wagman IH (1978) Nociceptive responses of neurons in medial thalamus and their relationship to spinothalamic pathways. J Neurophysiol 41:1592-1613.

Groenewegen HJ, Berendse HW (1994) The specificity of the "nonspecific" midline and intralaminar thalamic nuclei. Trends Neurosci 17:52-57. 
Grunwerg BS, Krauthamer GM (1992) Sensory responses of intralaminar thalamic neurons activated by the superior colliculus. Exp Brain Res 88:541-550.

Guillery RW (1995) Anatomical evidence concerning the role of the thalamus in corticocortical communication: a brief review. J Anat 187:583-592.

Guillery RW, Feig SL, Lozsádi DA (1998) Paying attention to the thalamic reticular nucleus. Trends Neurosci 21:28-32.

Horikawa K, Armstrong WE (1988) A versatile means of intracellular labeling: injection of biocytin and its detection with avidin conjugates. J Neurosci Methods 25:1-11.

Houser CR, Vaughn JE, Barber RP, Roberts E (1980) GABA neurons are the major cell type of the nucleus reticularis thalami. Brain Res 200:341-354.

Jahnsen H, Llinás R (1984) Electrophysiological properties of guineapig thalamic neurones: an in vitro study. J Physiol (Lond) 349:205-226.

Jones EG (1975) Some aspects of the organization of the thalamic reticular complex. J Comp Neurol 162:285-308.

Jones EG (1985) The thalamus. New York: Plenum.

Kha HT, Finkelstein DI, Tomas D, Drago J, Pow DV, Horne MK (2001) Projections from the substantia nigra pars reticulata to the motor thalamus of the rat: single axon reconstructions and immunohistochemical study. J Comp Neurol 440:20-30.

Kim U, McCormick DA (1998) The functional influence of burst and tonic firing mode on synaptic interactions in the thalamus. J Neurosci 18:9500-9516

Kolmac CI, Mitrofanis J (1997) Organisation of the reticular thalamic projection to the intralaminar and midline nuclei in rats. J Comp Neurol 377:165-178.

LaBerge D, Carter M, Brown V (1992) A network simulation of thalamic circuit operations in selective attention. Neural Comp 4:318-331.

Lee SM, Friedberg MH, Ebner FF (1994a) The role of GABA-mediated inhibition in the rat ventral posterior medial thalamus. I. Assessment of receptive field changes following thalamic reticular nucleus lesions. J Neurophysiol 71:1702-1715.

Lee SM, Friedberg MH, Ebner FF (1994b) The role of GABA-mediated inhibition in the rat ventral posterior medial thalamus. II. Differential effects of $\mathrm{GABA}_{\mathrm{A}}$ and $\mathrm{GABA}_{\mathrm{B}}$ receptor antagonists on responses of VPM neurons. J Neurophysiol 71:1716-1726.

Lizier C, Spreafico R, Battaglia G (1997) Calretinin in the thalamic reticular nucleus of the rat: distribution and relationship with ipsilateral and contralateral efferents. J Comp Neurol 377:217-233.

Lo F-S, Sherman SM (1994) Feedback inhibition in the cat's lateral geniculate nucleus. Exp Brain Res 100:365-368.

Macchi G, Bentivoglio M (1986) The thalamic intralaminar nuclei and the cerebral cortex. In: Cerebral cortex, Vol 5, Sensory-motor areas and aspects of cortical connectivity (Jones EG, Peters A, eds), pp 355-401. New York: Plenum.

MacLeod NK, James TA, Kilpatrick IC, Starr MS (1980) Evidence for a GABAergic nigrothalamic pathway in the rat. II. Electrophysiological studies. Exp Brain Res 40:55-61.

Matsumoto N, Minamimoto T, Graybiel AM, Kimura M (2001) Neurons in the thalamic CM-Pf complex supply striatal neurons with information about behaviourally significant sensory events. J Neurophysiol 85:960-976.

Minamimoto T, Kimura M (2002) Participation of the thalamic CM-Pf complex in attentional orienting. J Neurophysiol 87:3090-3101.

Miyashita E, Keller A, Asanuma H (1994) Input-output organization of the rat vibrissal motor cortex. Exp Brain Res 99:223-232.

Oertel WH, Tappaz ML, Berod A, Mugnaini E (1982) Two-color immunohistochemistry for dopamine and GABA neurons in rat substantia nigra and zona incerta. Brain Res Bull 9:463-474.

Peschanski M, Guilbaud G, Gautron M (1981) Posterior intralaminar region in rat: neuronal responses to noxious and nonnoxious cutaneous stimuli. Exp Neurol 72:226-238.

Pinault D, Deschênes M (1998a) Anatomical evidence for a mechanism of lateral inhibition in the rat thalamus. Eur J Neurosci 10:3462-3469.

Pinault D, Deschênes M (1998b) Projection and innervation patterns of individual thalamic reticular axons in the thalamus of the adult rat: a three-dimensional, graphic, and morphometric analysis. J Comp Neurol 391:180-203.

Pinault D, Bourassa J, Deschênes M (1995) The axonal arborization of single thalamic reticular neurons in the somatosensory thalamus of the rat. Eur J Neurosci 7:31-40.

Porter LL, White EL (1983) Afferent and efferent pathways of the vibrissal region of primary motor cortex in the mouse. J Comp Neurol 214:279-289.

Power BD, Kolmac CI, Mitrofanis J (1999) Evidence for a large projection from the zona incerta to the dorsal thalamus. J Comp Neurol 404:554-565.

Rose JE (1942) The ontogenetic development of the rabbit's diencephalon. J Comp Neurol 7:61-129.

Salt TE (1989) Gamma-aminobutyric acid and afferent inhibition in the cat and rat ventrobasal thalamus. Neuroscience 28:17-26.

Sanchez-Vives MV, McCormick DA (1997) Functional properties of perigeniculate inhibition of dorsal lateral geniculate nucleus thalamocortical neurons in vitro. J Neurosci 17:8880-8893.

Scheibel AB (1981) The problem of selective attention: a possible structural substrate. In: Brain mechanisms of perceptual awareness (Pompeiano O, Ajmone-Marsan C, eds), pp 319-326. New York: Raven.

Scheibel ME, Scheibel AB (1966) The organization of the nucleus reticularis thalami: a Golgi study. Brain Res 1:43-62.

Schlag J, Schlag-Rey M (1984) Visuomotor functions of central thalamus in monkey. II. Unit activity related to visual events, targeting, and fixation. J Neurophysiol 51:1175-1195.

Schlag J, Lehtinen I, Schlag-Rey M (1974) Neuronal activity before and during eye movements in thalamic internal medullary lamina of the cat. J Neurophysiol 37:982-995.

Schlag-Rey M, Schlag J (1977) Visual and presaccadic neuronal activity in thalamic internal medullary lamina of cat: a study of targeting. J Neurophysiol 40:156-173.

Schlag-Rey M, Schlag J (1984) Visuomotor functions of central thalamus in monkey. I. Unit activity related to spontaneous eye movements. J Neurophysiol 51:1149-1174.

Sherman SM (2001) Tonic and burst firing: dual modes of thalamocortical relay. Trends Neurosci 24:122-126.

Sherman SM, Guillery RW (1996) Functional organization of thalamocortical relays. J Neurophysiol 76:1367-1395.

Sherman SM, Guillery RW (1998) On the actions that one nerve cell can have on another: distinguishing "drivers" from "modulators." Proc Nat Acad Sci USA 95:7121-7126.

Sherman SM, Guillery RW (2001) Exploring the thalamus. San Diego: Academic.

Sherman SM, Koch C (1986) The control of retinogeniculate transmission in the mammalian lateral geniculate nucleus. Exp Brain Res 63:1-20.

Shosaku A (1986) Cross-correlation analysis of a recurrent inhibitory circuit in the rat thalamus. J Neurophysiol 55:1030-1043.

Skinner JE, Yingling CD (1977) Central gating mechanisms that regulate event-related potentials and behavior. A neural model for attention. Prog Clin Neurophysiol 1:30-69.

Steriade M, Parent A, Hada J (1984) Thalamic projections of nucleus reticularis thalami of cat: a study using retrograde transport of horseradish peroxidase and fluorescent tracers. J Comp Neurol 229:531-547.

Strick P (1976) Activity of ventrolateral thalamic neurons during arm movement. J Neurophysiol 39:1032-1044.

Vitek JL, Ashe J, DeLong MR, Alexander GE (1994) Physiologic properties and somatotopic organization of the primate motor thalamus. J Neurophysiol 71:1498-1513.

Vitek JL, Ashe J, DeLong MR, Kaneoke Y (1996) Microstimulation of primate motor thalamus: somatotopic organization and differential distribution of evoked motor responses among subnuclei. J Neurophysiol 75:2486-2495.

Warren RA, Jones EG (1994) Glutamate activation of cat thalamic reticular nucleus: effects on response properties of ventroposterior neurons. Exp Brain Res 100:215-226. 